BMJ Open

Diabetes

Research

\& Care

\title{
Insulin use and new diabetes after acceptance for bariatric surgery: comparison of outcomes after completion of surgery or withdrawal from the program
}

\author{
Jessica H Lee (D) , ${ }^{1}$ Rebekah Jaung, ${ }^{2}$ Grant Beban, ${ }^{3}$ Nicholas Evennett, ${ }^{3}$ \\ Tim Cundy ${ }^{1,2}$
}

To cite: Lee JH, Jaung R, Beban G, et al. Insulin use and new diabetes after acceptance for bariatric surgery: comparison of outcomes after completion of surgery or withdrawal from the program. BMJ Open Diab Res Care 2020;8:e01837. doi:10.1136/ bmjdrc-2020-001837

Received 15 August 2020 Revised 16 October 2020 Accepted 26 October 2020

Check for updates

(c) Author(s) (or their employer(s)) 2020. Re-use permitted under CC BY-NC. No commercial re-use. See rights and permissions. Published by BMJ.

${ }^{1}$ Auckland Diabetes Centre, Auckland City Hospital, Auckland, Aotearoa-New Zealand

${ }^{2}$ Faculty of Medical and Health Sciences, The University of Auckland, Auckland, AotearoaNew Zealand

${ }^{3}$ Hepatobiliary and Upper GI Unit, Department of General Surgery, Auckland City Hospital, Auckland, Aotearoa-New Zealand

Correspondence to Dr Jessica H Lee drjessica.lee2@gmail.com

\section{ABSTRACT}

Introduction In people accepted onto a bariatric surgery program we compared diabetes-related outcomes in those who completed surgery with those who withdrew before having surgery - examining rates of insulin use in people with type 2 diabetes (T2D), and rates of incident diabetes in people without pre-existing T2D.

Research design and methods 771 people were accepted onto the program. 463 people (60\%) had T2D at referral, of which $48 \%$ completed surgery and $52 \%$ withdrew. Of 308 people without T2D at referral, $49 \%$ completed surgery, and $51 \%$ withdrew. Rates of insulin use and incident diabetes were compared by Kaplan-Meier analyses. Among those with preexisting T2D, we examined rates of remission and relapse after surgery.

Results People without T2D who withdrew from the program had higher mean body mass index and glycated hemoglobin levels than those completing surgery $(p<0.005)$. The rate of incident diabetes at 5 years was $19 \%$ in those who withdrew versus $0 \%$ in those completing surgery $(p<0.001) .30 \%$ of people with T2D were taking insulin at referral and all stopped insulin after surgery. During follow-up, the rate of insulin (re) introduction was lower in those who completed surgery $(8 \%$ vs $26 \%$ at 5 years, $p<0.001$ ). Of those with T2D who completed surgery, $80 \%$ had remission, but $34 \%$ had relapsed by 5 years. Diabetes relapse was associated with less weight loss after surgery, a longer duration of T2D and previous insulin use. Conclusions Despite a high relapse rate, people with T2D who completed surgery had lower insulin use at 5 years than those withdrawing from the program. In people without T2D, bariatric surgery prevented incident diabetes. People without T2D who withdrew from the program were at greater risk of diabetes, suggesting those who could benefit the most in terms of T2D prevention are not completing bariatric surgery.

\section{INTRODUCTION}

A high proportion of people with type 2 diabetes (T2D) who undergo bariatric surgery can have remission of diabetes, or improvement in glycemic control. ${ }^{1-7}$ However, longer term studies have shown that the remission of diabetes is often not sustained. For example, a recent US study found that $35 \%$ of those who had remission

\section{Significance of this study}

What is already known about this subject?

- Bariatric surgery has beneficial effects on type 2 diabetes-related outcomes including diabetes remission and improvement in cardiometabolic risk profile.

- Previous studies have mostly compared diabetic outcomes before and after bariatric surgery.

What are the new findings?

- This study had a comparator group consisting of those who were accepted onto a publicly funded bariatric program but withdrew prior to having surgery.

- In keeping with previous studies, completion of bariatric surgery resulted in lower insulin use, lower rates of incident diabetes and higher rates of diabetes remission.

- Those withdrawing from the program were younger, more obese and had poorer glycemic control highlighting in the Aotearoa-New Zealand context that bariatric programs can struggle to reach those people who might benefit most.

How might these results change the focus of research or clinical practice?

- Contributes to a better understanding of the trajectory of diabetic outcome in relation to bariatric surgery, giving an insight into the natural history of diabetes if surgery were not to occur.

- Highlights the need for further work on overcoming specific barriers to bariatric surgery.

of diabetes after bariatric surgery had recurrence within 5 years, ${ }^{1}$ and recently published data from the Swedish Obese Subjects study showed overall relapse rate of $54 \%$ at 10 years. ${ }^{8}$ Risk factors for diabetes relapse after surgery include a longer duration of diabetes, preoperative insulin use, poor preoperative glycemic control, impaired $\beta$-cell function, greater preoperative weight and a lesser degree of postoperative weight loss. ${ }^{1-3}$ However, even if diabetes relapses it often requires less medication ${ }^{3910}$ and a recent study 
demonstrated that benefits relating to diabetes disease trajectory and accompanying cardiometabolic risk factors still remained despite relapse. ${ }^{11}$

In the majority of studies examining the long-term effects of bariatric surgery, diabetes status has been compared before and after surgery in individuals. While such analyses are informative, they may underestimate the broader impact of bariatric surgery on diabetes. A high rate of attrition in bariatric programs is common-typically only about half of those accepted go on to complete surgery. ${ }^{12-14}$ Over time, among those who dropped out before having surgery, new diabetes is likely to develop in some, and among those who already had diabetes at acceptance, it is likely to become more severe, necessitating the introduction of insulin treatment.

In our publicly funded bariatric program, the attrition rate after acceptance from 2007 to 2016 was 54\%; the reasons for attrition being predominantly disengagement, voluntary withdrawal, or failure to meet preoperative weight targets. ${ }^{14}$ Follow-up of this group, alongside the $46 \%$ who successfully completed surgery, affords a comparison that may better reflect the wider impact of surgery. In this paper, we have compared those who did and those who did not complete surgery, examining both the new development of diabetes and insulin initiation (an index of diabetes severity). Our hypotheses were that (1) among those without diabetes at the time of acceptance onto the program the incident rate for new diabetes would be higher in those not proceeding to surgery, and (2) among those with diabetes, the cumulative rate of insulin use would be greater in those not proceeding with surgery.

A number of recent studies have examined prediction models for diabetes relapse following bariatric surgery, consisting of preoperative factors such as diabetes duration, medication use, glycated hemoglobin (HbAlc) and postoperative factors including weight loss and regain. However, a recent study has shown low predictive performance of these models, and their use in clinical practice has been limited. ${ }^{8}$ More data and a better understanding of diabetes trajectory following bariatric surgery are needed to identify those at highest risk of diabetes relapse and to allow for appropriate monitoring and timely institution of treatment. We have also analyzed data among those with pre-existing T2D who underwent surgery, to better understand the rates, time course and factors associated with remission and relapse.

\section{RESEARCH DESIGN AND METHODS}

We used a database of people who had been accepted onto the publicly funded bariatric program at Auckland District Health Board (ADHB) from 1 May 2007 to 31 December 2016. To be considered for the bariatric program, potential candidates were referred to the ADHB bariatric service by their general practitioner or other medical specialists. The referrals were assessed by the bariatric team for eligibility. The criteria for acceptance into the bariatric program included body mass index (BMI) $\geq 35 \mathrm{~kg} / \mathrm{m}^{2}$, previous unsuccessful attempts at weight loss, and at least one obesity-related comorbidity, most commonly T2D and/or obstructive sleep apnea. These criteria remained unchanged throughout the duration of the study. People accepted onto the program attended clinic appointments with the bariatric surgeon, bariatric nurse specialist, dietician, and a health psychologist; after the first appointment, regular monitoring was maintained by one of the bariatric team members. In order to proceed to surgery, candidates had to fulfill a preoperative weight loss requirement of $10 \%$ of excess body weight above a BMI of $25 \mathrm{~kg} / \mathrm{m}^{2}$. Once waitlisted for surgery, a verylow-calorie dietary replacement (Optifast) was used for 3-6 weeks leading up to the surgery in order to reduce hepatic steatosis. The surgical procedures performed were either sleeve gastrectomy or Roux-en-Y gastric bypass. Insulin treatment was stopped either preoperatively (if glycemic control was good) or immediately postoperatively.

For the purpose of this study, follow-up started from the day of the procedure in those completing surgery, or from the day of referral in those not completing surgery and was continued to 31 December 2018 or the last day of contact prior to that date. The last day of contact was defined as whichever was the most recent of either a hospital communication indicating the patient had been seen, a community laboratory test completed, or a prescription lodged with a community pharmacy.

Laboratory results for HbA1c and pharmacy dispensing history (for insulin or oral hypoglycemic agents) were obtained from the shared medical record that includes data from the TestSafe system that archives all community medical laboratory tests and the lodging of prescriptions at community pharmacies in the northern part of Aotearoa-New Zealand. We also collected basic demographic data (age, gender, ethnicity, date of birth); information relating to diabetes (year of diagnosis, HbAlc at referral and at approximately yearly intervals, use of insulin at referral, and date of insulin resumption or start); BMI at referral and at approximately yearly intervals; and date and type of bariatric surgery (either Roux-en-Y bypass or sleeve gastrectomy). An HbAlc measurement of $\geq 6.7 \% \quad(50 \mathrm{mmol} / \mathrm{mol})$ was used as the diagnostic criterion for new T2D.$^{15}$ Ethnicity (self-identified) was classified as either: New Zealand European, Māori (the indigenous people of Aotearoa), Pasifika (of Pacific Island descent) or 'other' (who were mainly of south, south-eastern or east Asian descent).

\section{Statistical analysis}

The $\chi^{2}$ test was used for categorical variables, and t-test and analysis of variance were used for continuous variables. Kaplan-Meier curves were generated using the Stata program.

\section{RESULTS}

\section{Baseline characteristics}

Between 1 May 2007 and 31 December 2016, a total of 774 people were accepted onto the bariatric program; three with type 1 diabetes were excluded, leaving 771 patients for analysis. Four hundred and sixty-three $(60 \%)$ had T2D at the time of referral. Of those, $224(48 \%)$ completed surgery, and $239(52 \%)$ did not. Of the 308 
Table 1 Demographic features, glycemic control and insulin use at referral

\begin{tabular}{|c|c|c|c|}
\hline \multicolumn{3}{|c|}{ Subjects with type 2 diabetes at referral } & \multirow[t]{2}{*}{$P$ value } \\
\hline & Completed surgery $(n=224)$ & No surgery $(n=239)$ & \\
\hline Gender (male), n (\%) & $71(32)$ & $106(44)$ & 0.005 \\
\hline Age (years) ${ }^{*}$ & $45.3(8.7)$ & $45.1(9.1)$ & 0.885 \\
\hline Ethnicity, n (\%) & & & 0.000 \\
\hline Pasifika & $50(22.3)$ & $99(41.4)$ & \\
\hline European & 89 (39.7) & $60(25.1)$ & \\
\hline Māori & $50(22.3)$ & $44(18.4)$ & \\
\hline Other & 35 (15.6) & $36(15.1)$ & \\
\hline Body mass index $\left(\mathrm{kg} / \mathrm{m}^{2}\right)^{*}$ & $46.4(6.9)$ & $47.4(8.6)$ & 0.180 \\
\hline $\mathrm{HbA} 1 \mathrm{c}(\mathrm{mmol} / \mathrm{mol})^{\star}$ & $66(18)$ & $70(21)$ & 0.020 \\
\hline$(\%)^{\star}$ & $8.2(3.8)$ & $8.6(4.1)$ & \\
\hline \multirow[t]{2}{*}{ Insulin treated at referral, n (\%) } & 70 (31.3) & $70(29.3)$ & 0.646 \\
\hline & Completed surgery $(n=151)$ & No surgery $(n=157)$ & \\
\hline Gender (male), n (\%) & 45 (29.8) & $73(46.5)$ & 0.003 \\
\hline Age (years)* & $43.0(10.0)$ & $39.3(10.4)$ & 0.002 \\
\hline Ethnicity, n (\%) & & & 0.000 \\
\hline Pasifika & 21 (13.9) & $69(43.9)$ & \\
\hline European & $90(59.6)$ & $50(31.8)$ & \\
\hline Māori & $29(19.2)$ & $27(17.2)$ & \\
\hline Other & $11(7.3)$ & $11(7.0)$ & \\
\hline Body mass index $\left(\mathrm{kg} / \mathrm{m}^{2}\right)^{\star}$ & $48.1(6.3)$ & $51.9(9.3)$ & 0.000 \\
\hline $\mathrm{HbA} 1 \mathrm{c}(\mathrm{mmol} / \mathrm{mol})^{*}$ & $39(5)$ & $41(5)$ & 0.003 \\
\hline$(\%)^{\star}$ & $5.7(2.6)$ & $5.9(2.6)$ & \\
\hline
\end{tabular}

${ }^{*}$ Results expressed as mean $( \pm S D)$.

$\mathrm{HbA1c}$, glycated hemoglobin.

(40\%) without T2D at the time of referral, 151 (49\%) completed surgery, and 157 (51\%) did not. Of those who completed surgery, $53 \%$ of people with pre-existing T2D and $39 \%$ of those without pre-existing T2D had Rouxen-Y gastric bypass; the remainder had sleeve gastrectomy.

The baseline characteristics are summarized in table 1 . As reported previously, men and people of Pasifika descent were less likely to complete surgery irrespective of diabetes status. ${ }^{14}$ In people with diabetes, the proportion using insulin was similar in those completing and those not completing surgery, but mean HbAlc values were higher in the latter. In people without diabetes at baseline those not completing surgery were on average younger, more overweight and had a slightly higher mean HbAlc (table 1).

\section{Insulin use}

Of the 224 people with T2D who underwent surgery, $70(31 \%)$ were receiving insulin treatment at referral, all of whom stopped insulin perioperatively. During follow-up, 16 people $(7 \%)$ resumed $(n=15)$ or started insulin for the first time $(\mathrm{n}=1) ; 7$ within the first 4 months of surgery, and 13 within 5 years. Those who resumed or started insulin after surgery were older (mean $( \pm \mathrm{SD}) 50(7)$ vs 45 (9) years, $\mathrm{p}=0.034)$, had higher mean HbAlc at baseline (9.8 (3.5) vs 8.1 (3.7)\%; 84 (15) vs 65 (17) $\mathrm{mmol} / \mathrm{mol}, \mathrm{p}<0.001)$ and were more likely to have been on insulin prior to surgery (94\% vs $26 \%, \mathrm{p}<0.001)$.

Among the 239 people with T2D who did not undergo surgery, $70(29 \%)$ were on insulin treatment at time of referral (and continued during follow-up), and 44 (18\%) were subsequently prescribed it. The rate at which insulin was started (or restarted) was significantly lower in the group who had surgery $(\mathrm{p}<0.001)$ (figure 1$)$. At 5 years of follow-up, the Kaplan-Meier estimate of new insulin use was $26 \%$ (95\% CI 20\% to 35\%) in those who did not have surgery, compared with $8 \%$ (95\% CI $4 \%$ to $14 \%$ ) in those who had completed surgery. As $29 \%$ of people with T2D who did not have surgery were already on insulin, the cumulative rate of insulin use in this group after 5 years was $55 \%$.

The mean HbA1c remained stable during follow-up in people with T2D who did not have surgery, but in those who did undergo surgery it fell from $8.2 \%$ (66 mmol/ $\mathrm{mol})$ to $6.3 \%(45 \mathrm{mmol} / \mathrm{mol})(\mathrm{p}<0.001)$ by 1 year. There was a subsequent gradual rise in mean $\mathrm{HbAlc}$, but at 5 


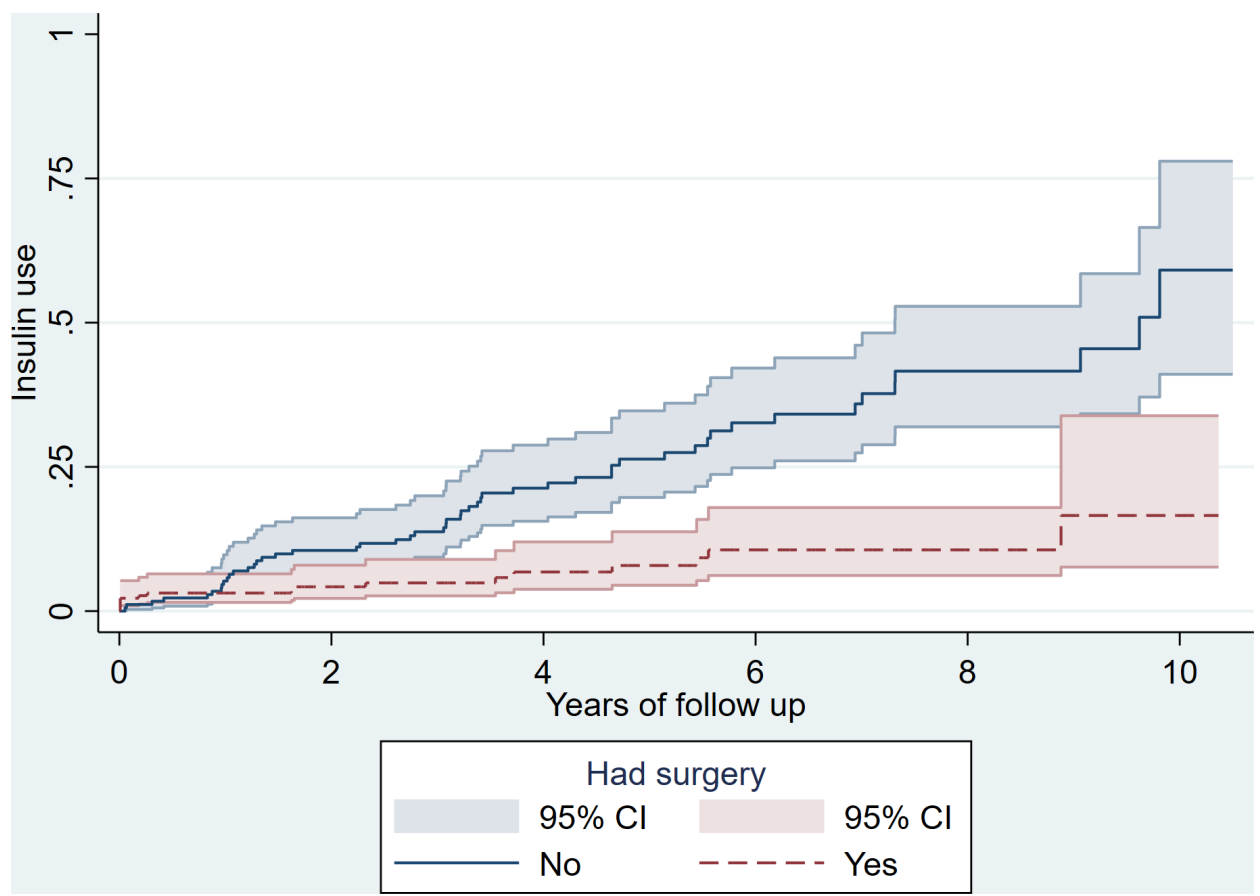

Figure 1 Kaplan-Meier estimate of insulin introduction or reintroduction in those with T2D at baseline. The rate was significantly lower in those completing surgery $(p<0.001)$. T2D, type 2 diabetes.

years it was still significantly lower than in the non-surgical group ( $7.2 \%$ vs $8.6 \%$; 55 vs $70 \mathrm{mmol} / \mathrm{mol}, \mathrm{p}<0.001)$.

\section{Incident diabetes}

There were 308 people without T2D at time of referral to the bariatric program, of whom $151(49 \%)$ underwent bariatric surgery and $157(51 \%)$ did not (table 1). HbA1c was measured approximately annually from follow-up, and patients who had $\mathrm{HbAlc} \geq 6.7 \% \quad(50 \mathrm{mmol} / \mathrm{mol}$ ) during follow-up were deemed to have developed diabetes. Twenty-three (15\%) of 157 people who did not have surgery developed diabetes during follow-up ( 6 by the first year, and 12 by the second year). None of the 151 people who had completed surgery developed diabetes. Of those without T2D at referral, the Kaplan-Meier estimate of incident diabetes at 5 years was $19 \%$ (95\% CI $12 \%$ to $27 \%$ ) in those who withdrew from the program versus $0 \%$ in those who completed surgery $(\mathrm{p}<0.001)$ (figure 2).

After 1 year of follow-up the between-group difference in mean HbAlc had increased from $2.3 \%(2 \mathrm{mmol} / \mathrm{mol})$ to $3.0 \%(9 \mathrm{mmol} / \mathrm{mol})(\mathrm{p}<0.001)$. Thereafter, the mean HbAlc remained stable in those who had surgery, but gradually increased into the pre-diabetes range in those who did not, with a between-group difference of $3.2 \%$ $(12 \mathrm{mmol} / \mathrm{mol})$ by 5 years $(\mathrm{p}<0.001)$.

\section{Diabetes remission}

Among the 224 people with T2D who underwent bariatric surgery, $179(80 \%)$ went into remission, defined as HbA1c $<6.7 \%(50 \mathrm{mmol} / \mathrm{mol})$ in the absence of insulin or other diabetes medication. The median follow-up period was 42 months in this group: $170(95 \%)$ of the 179 people who went into remission did so within 1 year of bariatric surgery.

Those who went into remission were more likely to be female, have greater weight loss within the first year of surgery, have a shorter duration of diabetes, lower HbA1c and no insulin requirement prior to surgery (table 2).

\section{Diabetes relapse}

Out of the 179 people whose diabetes had gone into remission after bariatric surgery, 44 subsequently had relapse of T2D. The median follow-up period for those who had gone into remission was 43 months. KaplanMeier analysis showed a relapse rate of 34\% (95\% CI 26\% to $44 \%$ ) at 5 years, and $47 \%$ (95\% CI $34 \%$ to $63 \%$ ) at 10 years (figure 2 ). Comparison was made between those who had relapsed and those who had not. Given that the relapse rate continued to increase for several years after surgery, only the 71 people with minimum 5 years of follow-up were included in this analysis. This showed that those who relapsed by 5 years were more likely to have had longer duration of diabetes (mean $( \pm \mathrm{SD}) 7.6$ (5.0) vs 4.8 (4.6) years, $\mathrm{p}=0.02$ ), to have been on insulin at referral $(22.2 \%$ vs $13.6 \%, \mathrm{p}=0.035)$, and to have had a smaller drop in BMI by $3.5-4.0 \mathrm{~kg} / \mathrm{m}^{2}(\mathrm{p}=0.001$ at 1 year, $\mathrm{p}=0.009$ at 3 years). Of the 44 people who had relapsed within 5 years, 34 were started on an oral hypoglycemic agent or insulin; there was no statistically significant difference in BMI change, duration of diabetes, rates of insulin use at referral, or baseline demographic characteristics between those requiring medication after relapse compared with those who did not. 


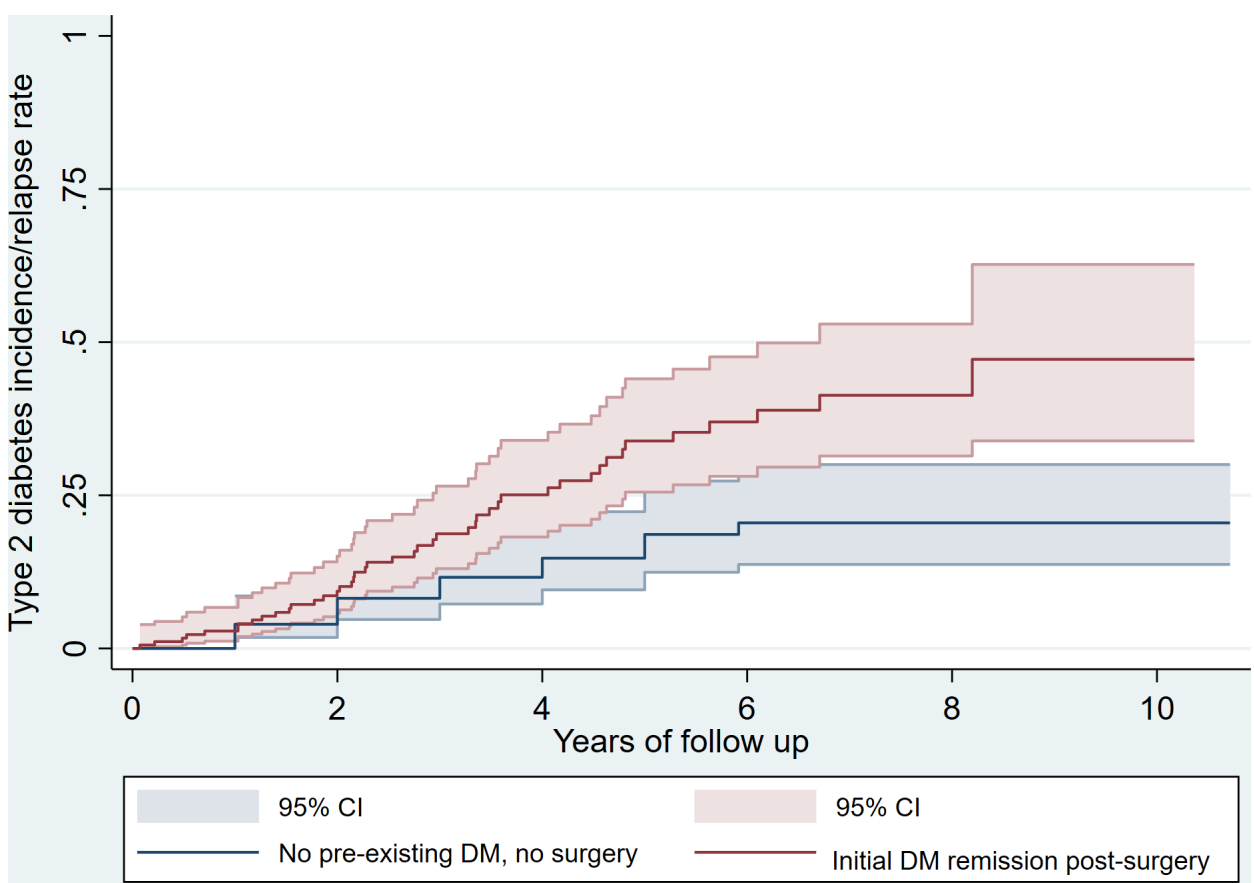

Figure 2 Kaplan-Meier estimate of diabetes relapse in subjects with initial diabetes remission after surgery, and development of new diabetes in people who did not have diabetes at referral and did not proceed to surgery. DM, diabetes mellitus.

\section{CONCLUSIONS}

It is well established that after bariatric surgery T2D can resolve and that over time it may recur. Tools have been developed to predict the likelihood of remission of diabetes, and risk factors for postsurgery relapse have been identified. ${ }^{1-38}$ While this information is helpful to clinicians and prospective patients, and demonstrates the benefits of surgery on diabetes, it gives an incomplete picture in that it does not take into account the likely natural history had surgery not happened. Although often unreported, there is substantial preoperative attrition once people have been referred and accepted for bariatric surgery, with rates as high as $50 \%-64 \% .{ }^{12-14}$ In this context, preoperative attrition is defined as when, after voluntarily seeking bariatric surgery and having been accepted onto a program, a person withdraws from

Table 2 Characteristics of subjects who did or did not achieve remission of type 2 diabetes following surgery

\begin{tabular}{|c|c|c|c|}
\hline & \multicolumn{3}{|c|}{ People with pre-existing T2D who underwent surgery } \\
\hline & No remission $(n=45)$ & Remission ( $n=179)$ & $P$ value \\
\hline Male $(n, \%)$ & 21 & 49 & 0.013 \\
\hline Age at referral (years) ${ }^{\star}$ & $47.5(8.3)$ & $44.7(8.7)$ & 0.053 \\
\hline Ethnicity (\%) & & & 0.384 \\
\hline European & $21(46.7)$ & $68(38.0)$ & \\
\hline Pasifika & $12(26.7)$ & $38(21.2)$ & \\
\hline Māori & $7(15.6)$ & $43(24.0)$ & \\
\hline Other & $5(11.1)$ & $30(16.8)$ & \\
\hline $\mathrm{BMI}$ at referral $\left(\mathrm{kg} / \mathrm{m}^{2}\right)^{*}$ & $42.8(5.3)$ & $47.3(7.0)$ & 0.000 \\
\hline Change in BMl at 1 year $\left(\mathrm{kg} / \mathrm{m}^{2}\right)^{*}$ & $-11.8(3.1)$ & $-13.9(4.7)$ & 0.005 \\
\hline Change in BMl at 3 years $\left(\mathrm{kg} / \mathrm{m}^{2}\right)^{*}$ & $-10.8(2.4)$ & $-11.1(4.8)$ & 0.866 \\
\hline Change in $\mathrm{BMI}$ at 5 years $\left(\mathrm{kg} / \mathrm{m}^{2}\right)^{*}$ & $-9.9(3.8)$ & $-9.0(5.3)$ & 0.649 \\
\hline Mean $\mathrm{HbA} 1 \mathrm{c}$ at referral $(\mathrm{mmol} / \mathrm{mol})^{\star}$ & $79(15)$ & $63(17)$ & 0.000 \\
\hline$(\%)^{*}$ & $9.4(3.5)$ & $7.9(3.7)$ & \\
\hline On insulin at referral, n (\%) & $36(80)$ & $34(19.0)$ & 0.000 \\
\hline Roux-en-Y bypass, n (\%) & $32(71)$ & $86(48)$ & 0.006 \\
\hline Duration of diabetes before surgery (years) & $10.1(4.6)$ & $6.1(4.8)$ & 0.000 \\
\hline
\end{tabular}

${ }^{*}$ Results expressed as mean $( \pm \mathrm{SD})$.

BMI, body mass index; hbA1c, glycated hemoglobin; T2D, type 2 diabetes. 
that program before undergoing surgery. In this paper we used data from people who did not proceed with surgery but who were enrolled in the same bariatric program as those who did. Although not randomized, this approach provides an interesting comparator population.

We studied two groups: those who already had T2D, and those without diabetes at the time of referral to the bariatric program. In the latter, by comparing people who underwent surgery with those who withdrew from the program, we documented that in the no surgery group the incidence of T2D was substantial $(19 \%$ at 5 years) and that over time mean HbA1c values increased into the pre-diabetes range. In contrast, no incident diabetes occurred during follow-up of those completing surgery, indicating that surgery is likely to have prevented the development of diabetes. There are caveats to these data: those not proceeding to surgery were more likely to be men and were, on average younger, with higher BMI and slightly higher HbAlc-all of which have been identified in our community as risk factors for progression from pre-diabetes to diabetes. ${ }^{16}$ Previous studies looking at the rate of incident diabetes with bariatric surgery have reported HRs between 0.17 and 0.68 compared with BMImatched controls from the community. ${ }^{17-19}$

In those with T2D at the time of referral approximately $30 \%$ were already using insulin, suggesting diabetes of long duration and/or poor $\beta$-cell reserve. Throughout follow-up, the proportion of people using insulin was significantly higher in those who did not have surgery than in those who completed surgery by approximately sevenfold at the 5-year follow-up, showing that bariatric surgery has marked benefits in improving diabetes severity. Based on the Kaplan-Meier estimates, the benefit is sustained over at least 10 years: the mean HbAlc remained lower at all time points in those with T2D who underwent surgery compared with those who had not, despite a continued increase in diabetes relapse over several years in those achieving initial diabetes remission. This is in keeping with a recent study showing sustained benefits with regard to diabetes control and cardiometabolic risk factors despite the recurrence of diabetes after bariatric surgery. ${ }^{11}$

Eighty percent of those with pre-existing T2D who completed surgery had remission, the majority within the first year of surgery, in agreement with previous observations. ${ }^{1-3}$ The timing of remission parallels the pattern of weight loss which is also greatest within the first year of surgery, ${ }^{2}{ }^{17}$ and is in keeping with the positive association that we observed between remission and change in BMI 1 year after surgery. Remission was also associated with a shorter duration of diabetes, a lower mean HbAlc and a lower rate of insulin use at referral. Lower rates of Roux-en-Y bypass surgery were seen in the group who had gone into remission, which was unexpected as this procedure is generally reported to result in greater weight loss and higher diabetes remission rates than sleeve gastrectomy. ${ }^{20-22}$ Our results are at least in part attributable to the fact that those who underwent Roux-en-Y had higher rates of insulin use $(41.5 \%$ vs $19.8 \%)$, higher average HbA1c ( $8.4 \%$ vs $7.9 \%, 69$ vs $63 \mathrm{mmol} / \mathrm{mol})$ and a longer duration of diabetes ( 7.6 vs 6.2 years) than those having sleeve gastrectomy. In addition, the sample size was small. We also acknowledge that the HbAlc cut-off for defining diabetes remission was higher in comparison to other studies $^{1611}$ that have used HbAlc of $<6.0 \%-6.5 \%$ $(42-48 \mathrm{mmol} / \mathrm{mol})$ to define remission. Our HbAlc cutoff for remission was $<6.7 \%(50 \mathrm{mmol} / \mathrm{mol})$, in accordance with local diagnostic criteria for T2D. This may have increased the absolute numbers of remission but is unlikely to have made a clinically significant difference to the overall findings. Kaplan-Meier analysis of diabetes relapse following initial remission showed a continued increase in relapse rates for at least 10 years, with some flattening of the curve observed from 5 to 6 years. A longer follow-up study consisting of a greater number of patients is required to define a more accurate trajectory of relapse. We found statistically significant associations between diabetes relapse by 5 years and a longer duration of T2D, greater rates of insulin use at referral, and less reduction in BMI at 1 and 3 years following surgeryfindings which are in line with previously identified risk factors for relapse.

Overall, completion of bariatric surgery was associated with significantly better diabetes-related outcomes in terms of insulin use, average HbA1c over 5 years, and incident diabetes. Analysis of data on diabetes remission and relapse confirmed their association with duration of diabetes, prior insulin use and weight loss at 1 year. Further research into the time trajectory of relapse, especially in relation to postoperative weight changes, could potentially improve the performance of current diabetes relapse prediction models such as DiaRem, Ad-DiaRem and DiaBetter which are mostly based on preoperative characteristics such as diabetes duration and medication use before surgery. ${ }^{23-25}$

Lastly, this study gives a better understanding of the trajectory of diabetic outcomes with an interesting comparison group, giving an insight into the natural history of diabetes if surgery were not to occur. Those who did not undergo surgery were more likely to have higher baseline HbAlc and to be of Pasifika descent, a population known to have high rates of diabetes and to be at a socioeconomic disadvantage in New Zealand, ${ }^{26} 27$ and this may have exaggerated the difference in diabetes outcome between the two groups. That being said, it emphasizes concern that people who already have worse glycemic control and are of lower socioeconomic status are less likely to proceed to bariatric surgery, and hence are more likely to have poorer diabetes outcomes, leading to further health disparities. Further studies are required to help determine specific barriers to bariatric surgery in disadvantaged groups and efforts are needed to alleviate them. Factors of likely import include health literacy, access to healthcare, language barriers and indirect costs of bariatric surgery. In our previous study looking at attrition from the bariatric program the most 
common reasons for attrition were disengagement with the service $(44 \%)$, voluntary withdrawal $(38 \%)$ and failure to meet weight loss targets $(17.4 \%) .{ }^{14}$ Since the publication of that paper, the requirement to reach a target weight before surgery has been discontinued in an effort to boost retention in the program.

In summary, among patients who were accepted into our publicly funded bariatric program, those with T2D who went onto complete surgery had significantly less insulin use over time and lower average HbAlc up to at least 10 years of follow-up, despite a substantial rate of relapse. Bariatric surgery was also effective in preventing the development of T2D. Of those with pre-existing diabetes who had completed surgery, those with shorter duration of diabetes, lower baseline HbAlc and greater weight loss in the first year after surgery were more likely to go into remission; maintenance of remission by 5 years was associated with the same characteristics.

Acknowledgements We thank Yijao Wang, William Rogerson and Greg Gamble for their assistance with establishing the bariatric surgery database.

Contributors JHL contributed to data analysis, interpretation, literature search and writing of the manuscript. RJ contributed to statistical analysis and processing. NE and GB facilitated data acquisition and contributed to final editing. TC designed the study, edited the manuscript and contributed to data collection, analysis and interpretation. All authors have reviewed the article and gave approval for submission of this version. JHL is the guarantor of this article, had full access to the data involved and takes responsibility for the contents of the article.

Funding The authors have not declared a specific grant for this research from any funding agency in the public, commercial or not-for-profit sectors.

Competing interests None declared.

Patient consent for publication Not required.

Ethics approval The study was approved by the New Zealand Health and Disabilities Ethics Committee (reference number 18/NTA/186).

Provenance and peer review Not commissioned; externally peer reviewed.

Data availability statement All data relevant to the study are included in the article.

Open access This is an open access article distributed in accordance with the Creative Commons Attribution Non Commercial (CC BY-NC 4.0) license, which permits others to distribute, remix, adapt, build upon this work non-commercially, and license their derivative works on different terms, provided the original work is properly cited, appropriate credit is given, any changes made indicated, and the use is non-commercial. See: http://creativecommons.org/licenses/by-nc/4.0/.

ORCID iD

Jessica H Lee http://orcid.org/0000-0001-8643-1773

\section{REFERENCES}

1 Arterburn DE, Bogart A, Sherwood NE, et al. A multisite study of long-term remission and relapse of type 2 diabetes mellitus following gastric bypass. Obes Surg 2013;23:93-102.

2 Pessoa BM, Browning MG, Mazzini GS, et al. Factors mediating type 2 diabetes remission and relapse after gastric bypass surgery. $J$ Am Coll Surg 2020;230:7-16.

3 Shah A, Laferrère B. Diabetes after bariatric surgery. Can J Diabetes 2017;41:401-6.

4 Rubino F, Nathan DM, Eckel RH, et al. Metabolic surgery in the treatment algorithm for type 2 diabetes: a joint statement by international diabetes organizations. Obes Surg 2017;27:2-21.
5 Cummings DE, Rubino F. Metabolic surgery for the treatment of type 2 diabetes in obese individuals. Diabetologia 2018;61:257-64.

6 Schauer PR, Bhatt DL, Kirwan JP, et al. Bariatric surgery versus intensive medical therapy for diabetes- 5-year outcomes. $N$ Engl $\mathrm{J}$ Med 2017;376:641-51.

7 Sheng B, Truong K, Spitler $\mathrm{H}$, et al. The long-term effects of bariatric surgery on type 2 diabetes remission, microvascular and macrovascular complications, and mortality: a systematic review and meta-analysis. Obes Surg 2017;27:2724-32.

8 Sjöholm K, Svensson P-A, Taube M, et al. Evaluation of prediction models for type 2 diabetes relapse after post-bariatric surgery remission: a post hoc analysis of 15-year follow-up data from the Swedish obese subjects (SOS) study. Obes Surg 2020;30:3955-60.

9 Mingrone G, Panunzi S, De Gaetano A, et al. Bariatric-metabolic surgery versus conventional medical treatment in obese patients with type 2 diabetes: 5 year follow-up of an open-label, singlecentre, randomised controlled trial. Lancet 2015;386:964-73.

10 Holman RR, Paul SK, Bethel MA, et al. 10-Year follow-up of intensive glucose control in type 2 diabetes. N Engl J Med 2008;359:1577-89.

11 Aminian A, Vidal J, Salminen P, et al. Late relapse of diabetes after bariatric surgery: not rare, but not a failure. Diabetes Care 2020;43:534-40.

12 Pitzul KB, Jackson T, Crawford S, et al. Understanding disposition after referral for bariatric surgery: when and why patients referred do not undergo surgery. Obes Surg 2014;24:134-40.

13 Sadhasivam S, Larson CJ, Lambert PJ, et al. Refusals, denials, and patient choice: reasons prospective patients do not undergo bariatric surgery. Surg Obes Relat Dis 2007;3:531-5.

14 Taylor T, Wang Y, Rogerson W, et al. Attrition after acceptance onto a publicly funded bariatric surgery program. Obes Surg 2018;28:2500-7.

15 Braatvedt GD, Cundy T, Crooke M, et al. Understanding the new $\mathrm{HbA1c}$ units for the diagnosis of type 2 diabetes. $N Z$ Med $J$ 2012;125:70-80.

16 Teng A, Blakely T, Scott N, et al. What protects against prediabetes progressing to diabetes? observational study of integrated health and social data. Diabetes Res Clin Pract 2019;148:119-29.

17 Douglas IJ, Bhaskaran K, Batterham RL, et al. Bariatric surgery in the United Kingdom: a cohort study of weight loss and clinical outcomes in routine clinical care. PLoS Med 2015;12:e1001925.

18 Carlsson LMS, Peltonen M, Ahlin S, et al. Bariatric surgery and prevention of type 2 diabetes in Swedish obese subjects. N Engl J Med 2012;367:695-704.

19 Booth $\mathrm{H}$, Khan O, Prevost T, et al. Incidence of type 2 diabetes after bariatric surgery: population-based matched cohort study. Lancet Diabetes Endocrinol 2014;2:963-8.

20 Ardestani A, Rhoads D, Tavakkoli A. Insulin cessation and diabetes remission after bariatric surgery in adults with insulin-treated type 2 diabetes. Diabetes Care 2015;38:659-64.

21 Roslin MS, Cripps CN. Bariatric surgery in managing diabetes mellitus. Curr Opin Gastroenterol 2016;32:481-6.

22 McTigue KM, Wellman R, Nauman E, et al. Comparing the 5-year diabetes outcomes of sleeve gastrectomy and gastric bypass: the National patient-centered clinical research network (PCORNet) bariatric study. JAMA Surg 2020;155:e200087.

23 Aron-Wisnewsky J, Sokolovska N, Liu Y, et al. The advancedDiaRem score improves prediction of diabetes remission 1 year post-Roux-en-Y gastric bypass. Diabetologia 2017;60:1892-902.

24 Dicker D, Golan R, Aron-Wisnewsky J, et al. Prediction of long-term diabetes remission after RYGB, sleeve gastrectomy, and adjustable gastric banding using DiaRem and Advanced-DiaRem scores. Obes Surg 2019;29:796-804.

25 Pucci A, Tymoszuk U, Cheung WH, et al. Type 2 diabetes remission 2 years post Roux-en-Y gastric bypass and sleeve gastrectomy: the role of the weight loss and comparison of DiaRem and DiaBetter scores. Diabet Med 2018;35:360-7.

26 Marriot L, Sim D. Indicators of inequality for Māori and pacific people. J New Zeal Stud 2015;20:24-50.

27 Chan WC, Jackson G, Wright CS, et al. The future of population registers: linking routine health datasets to assess a population's current glycaemic status for quality improvement. BMJ Open 2014;4:e003975. 